Ван Вэй - аспирант социологического факультета Московского государственного университета им. М.В. Ломоносова (119234, Россия, г. Москва, ул. Ленинские Горы, 1, стр. 33; wang.wei@bk.ru)

\title{
НЕКОТОРЫЕ ВОПРОСЫ СОЦИАЛЬНО- ПОЛИТИЧЕСКОГО КУРСА «КИТАЙСКАЯ МЕЧТА О ВЕЛИКОМ ВОЗРОЖДЕНИИ КИТАЙСКОЙ НАЦИИ»
}

Аннотация. В статье рассматриваются концепции «Китайская мечта» и «Один пояс - один путь» в их исторической трансформации. Многие политологи воспринимали концепцию «китайской мечты» как возможный отказ от национальных традиций. Вестернизация Китая позволила ему заимствовать все лучшее из западного опыта в целях сокращения разрыва с ведущими державами. Выбранная стратегия может быть спроецирована на другие государства, что со временем нивелирует эксклюзивность Китая. Однако соперничество между великими державами - США, Россией и Китаем - и гонка вооружений могут сделать эту стратегию бессмысленной и создадут угрозу для сохранения цивилизации и мира во всем мире. Поэтому необходимо перейти от «национальной мечты» к построению системы стабильного сосуществования и мира. Отмечено, что концепция «Один пояс - один путь» может выступать как механизм реализации «китайской мечты» либо как ее альтернатива, что покажет дальнейшая реализация проекта.

Ключевые слова: “китайская мечта», социально-политический курс, китайская нация, национальное возрождение, КНР, Китай, проект «Один пояс - один путь», вестернизация

«K итайская мечта» стала предметом публичных дискуссий благодаря горячей поддержке данной концепции новым председателем Китая Си Цзиньпином, который напомнил о более чем вековом китайском стремлении к национальному возрождению. В данной статье мы подробно рассмотрим данный курс.

Действующий социально-политический курс, которым следует Китайская Народная Республика (КНР), называется «Китайская мечта о великом возрождении китайской нации», или, в более краткой формулировке, «Китайская мечта». Впервые этот термин был озвучен в конце 2012 г. Си Цзиньпином, лидером так называемого пятого поколения руководителей, и уже в ноябре 2013 г. был дан старт процессу проведения реформ в Китае, связанных с новой концепцией. В рамках первого публичного представления этой концепции Си Цзиньпин дал определение концепции: «...осуществление великого возрождения китайской нации - это величайшая мечта китайской нации, начиная с нового времени». Корни этой китайской мечты кроются в борьбе, которую ведет китайский народ вот уже 170 лет, начиная с времен «опиумных войн» (1839-1842 и 1856-1860 гг.). Окончание борьбы должно произойти через 37 лет, в 2049 г. - к столетнему юбилею образования КНР.

Цели концепции «Китайская мечта» представлены на рис. 1.

Данная концепция призвана модернизировать политическое поведение людей, что неизбежно должно повлиять на их политическую культуру. Подобная трансформация провоцирует ряд конфликтов, вызванных восприятием политики и отношением к ней в КНР. Ценности и ориентации политической культуры Китая не отличаются от большинства ценностей и ориентаций других стран Востока, которые в основном направлены на сохранение традиций [Политология 2013: 367].

Однако до недавнего времени в Китае наблюдался конфликт между классическими установками общества и официальными нормами, насаждаемыми 
нынешним режимом [Чжао Чуньфу 1999: 123-126]. Поддерживаемой традицией является конфуцианство [Needham 1956: 165]. В рамках идеологии, сконструированной КПК ранее, требование почитания старины конфуцианцами, равно как и требование почитать самих конфуцианцев, противоречило установке на создание современного общества. Официально в КНР общество зиждилось на идее равенства, а не на принятых последователями Конфуция принципах иерархичности. Стоит отметить, что преднамеренно или нет, но заимствование деятелями КПК «стратагем» у традиционных учений происходит регулярно, преимущественно без официального признания этого факта. Исследователям приходится предполагать и догадываться о реальном обосновании упоминания того или иного термина или призыва, а также об идейной подоплеке какоголибо политического или другого действия, санкционированного партией.

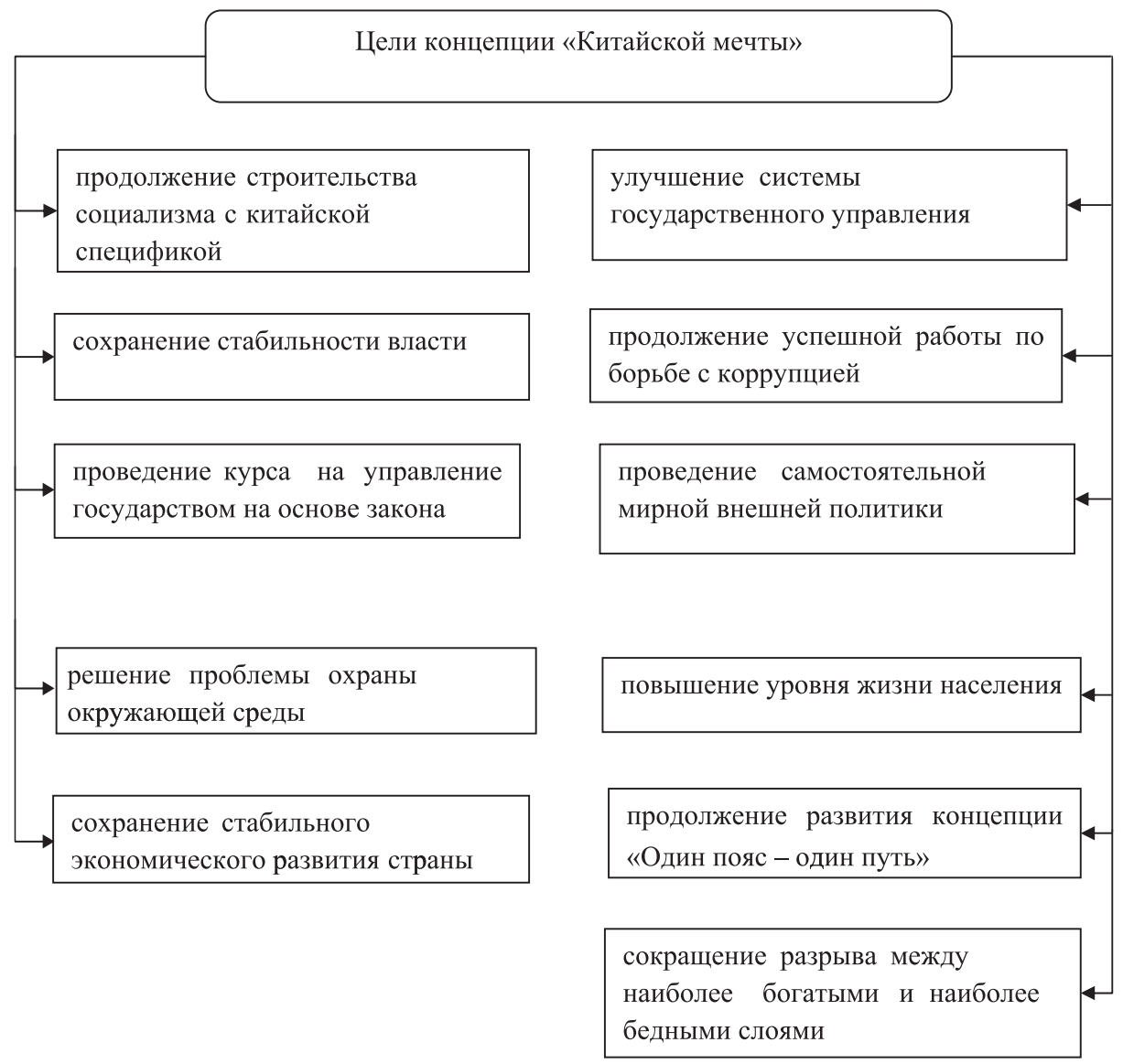

Рисунок 1. Цели концепции «Китайская мечта»

Идея преемственности и традиционности в концепции «Китайской мечты» кроется в ее названии, где содержится призыв к возрождению величия страны. С учетом многократных упоминаний о «веке унижений» великим полагается блестящее прошлое Китая. Во всяком случае, прошлое страны видится великолепным практически каждому китайцу; причины такого мировоззрения заключены в традиции. Вера в «великолепное (великое) прошлое» имеет место 
не одно тысячелетие: она получила особое развитие на рубеже XIX и XX вв., когда происходили поиски аналогов западноевропейской общественной мысли [Борох 1984: 89]. Преемственность вместе с опытом Поднебесной по поглощению, окитаизированию собственных захватчиков позволяла на протяжении веков формировать в сознании китайцев представление о Китае как о великой цивилизации, центре мира [Киссинджер 2014: 25-27]. Все это способствовало вере в невозможность создания чего-либо нового, не имевшего прецедентов в прошлом [Ознос 2016: 87-90]. Расширяя тезис о возрождении нации в ее лучшем виде, то есть до уровня некоторого гипотетического прошлого (очевидно, что брать в расчет времена мифической древности нет никакого смысла), мы с необходимостью приходим к положению о том, что китайцам нужно возрождать страну с учетом конфуцианских представлений о государстве, т.к. единый Китай до событий Синьхайской революции существовал именно под флагом учения Конфуция. Косвенно возрождение конфуцианского учения (правда, сейчас уместнее говорить о его популяризации и пропаганде) подтверждается все набирающей обороты своеобразной пиар-кампанией, в рамках которой появляются памятники Конфуцию, вновь открываются храмы в его честь. Родина мыслителя становится местом паломничества, тематические книги издаются большими тиражами, снимаются фильмы и сериалы [Ковалев, Абрамова 2017]. Впрочем, эти проявления поверхностны: глубинные изменения происходят в политической сфере, где древнее социально-политическое учение упрочивает свои позиции, а роль как традиции вообще, так и традиционной идеологии в частности становится все более заметной.

Одно из центральных мест в концепции «китайской мечты» занимает представление о сяо-кан, которое является наследием предыдущих лидеров партии. Сяо-кан - важное понятие социально-политического аспекта традиционных китайских учений. Нынешняя идеология придерживается той позиции, что сяо-кан - это, прежде всего, определенная программа по улучшению благосостояния общества, политический инструмент, однако само понятие подразумевает достаточно большое число трактовок и может иметь различное смысловое наполнение. Значение сяо-кан корректировалось в зависимости от внешних обстоятельств и определялось уже не один раз. Изначальная утопическая формулировка с годами обретала материальное воплощение и в результате в XX в. обзавелась четким денежным эквивалентом, который регулярно изменяется. Однако теперь, когда происходят достаточно серьезные сдвиги в идеологической платформе КПК, важным становится философский аспект понимания сяо-кан. Идеологическое значение понятия сяо-кан (помимо его важности в экономической жизни КНР) можно раскрыть через подходы к его пониманию у нескольких авторов и интерпретаторов. Первым дал социально-политическое понимание сяо-кан Конфуций. В его трактовке это общество, где долг (и 義) и ритуал (ли 禮) являются основными ориентирами, благодаря которым определяются положение в обществе и должности в государственном аппарате, утверждается режим правления, укрепляются семьи, формируются земельные наделы. У Конфуция сяо-кан обычно принято понимать как общество, которое пришло на смену обществу да-тун (大同), при котором «действовало Великое дао (道), Поднебесная принадлежала всем» (или «шли по Великому пути, Поднебесная была общей»), а собственно сяо-кан трактуется как период, «когда Великое дао уже скрылось, Поднебесная принадлежит семьям».

Мэн-цзы описывал сяо-кан так: истинным правителем будет называться тот, кто позволит народу не страдать от голода и холода и не станет отнимать у народа время на то, чтобы заняться собственным хозяйством, т.е. даст возможность народу самому заниматься собственным благополучием, не чиня ему 
препятствий. Позиция Мэн-цзы заключалась в утверждении «гуманного правления», в рамках которого следовало смягчить наказания, уменьшить налоги и т.д. Он также уповал на значимость материального фактора в жизни народа и утверждал, что народ обладает «постоянным имуществом» при правильном общественном устройстве. Идеи древних мудрецов практически дублированы в установках, озвученных Дэн Сяопином. Использование понятия сяо-кан в начале проведения реформ емко описывало цели и средства реализации изменений в КНР. Однако важно понимать, что сяо-кан является обществом, которое ушло (как обычно это понимается) от самого благополучного своего состо-

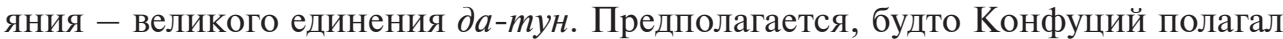

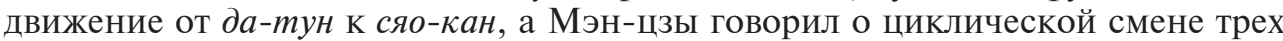
периодов: к вышеуказанным эпохам добавлялся век смуты. Новизну в конфуцианскую теорию социальных утопий привнес Кан Ю-вэй. Он предполагал,

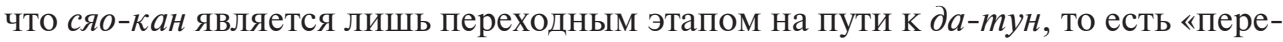
вернул» ход истории - от периода хаоса и смуты к сяо-кан и затем к $\partial a-m y н$. Понятие да-тун использовалось на более ранних этапах развития идеологической платформы КПК: объединение народа ради отпора иностранным захватчикам, объединение в народные коммуны ради построения коммунистического общества.

Таким образом, история Китая способствует сплочению нации, позволяет использовать исторический опыт и сформулировать национальную идею, которая объединит китайскую нацию.

Появилось немало мыслителей, идеи которых способствовали иному формированию сознания китайцев, трансформации национальной культуры. Одним из них является «ученый-энциклопедист, политик Вэй Юань, выдвинувший культурную программу модернизации страны путем заимствования западных научно-технических достижений» [Скрипкарь, Шамшурин 2016]. Необходимость принятия такой политики была обусловлена потребностью в модернизации государства, в котором царила нищета и отсталость. Наиболее важная проблема заключалась в определении содержания заимствований, с тем чтобы страна не потеряла свою национальную идентичность и могла эффективно использовать заимствования для достижения своих интересов. Вестернизация страны при сохранении собственных традиций является способом осуществления скорейшей модернизации страны. Именно такой взгляд и был положен в основу общей мечты китайского народа в XVIII в. Такая идеология воплотилась в формуле «китайские ценности и западные средства», т.е. принятие западного опыта при максимальном сохранении конфуцианских ценностей. Реформаторы - известные ученые Кан Ювэй и Лян Цичао - видели необходимость в модернизации политики, науки, образования, вооружения. Кан Ювэй и Лян Цичао предложили осуществление политических реформ, которые должны были изменить монархический режим и установить конституционный строй.

Таким образом, реформы проводились под лозунгом «древность на службе современности», который был ориентирован на развитие новых идей путем их переосмысления. Изменение устаревших традиций стало основным содержанием «Движения 4 мая» и «Движения за новую культуру», имевшими антиконфуцианскую направленность. В борьбе с технологической отсталостью на помощь Китаю пришел СССР: огромное число советских ученых, инженеров, педагогов помогали поднимать экономику Китая. Было внедрено более 100 проектов в оборонной промышленности, авиации, судостроении, металлургии, машиностроении, энергетике, электротехнической, химической и легкой промышленности, фармацевтике и других отраслях. «Экономические реформы 
в КНР, начавшиеся в конце 70-х годов прошлого столетия, сопровождались политическими изменениями внутри страны, которые требовали нового идеологического обеспечения этого процесса» [Киссинджер 2014]. Появились «концепция трех представительств», «научная концепция развития» и др. Сегодня в основе «китайской мечты» лежит идеология построения могущественного культурного государства с максимальным использованием «мягкой силы». «Мягкая сила» выступает как инструмент, способный превратить государство в могучую, развитую страну без применения военной мощи, скорее, используя культурный потенциал и распространение своего присутствия путем осуществления экономических, культурных и других глобальных проектов по всему миру» [Ознос 2016].

Рост «мягкой силы» мыслится как создание системы стержневых социалистических ценностей, увеличение притягательных и консолидирующих сил социалистической идеологии; формирование гармоничной культуры, воспитание цивилизованных отношений; распространение национальной культуры и строительство общего духовного очага китайской нации; продвижение новаторства в культуре, усиление ее жизненной силы. Известно, что «наиболее действенным глобальным проектом КНР по выходу китайской культуры “вовне" является создание сети Институтов Конфуция во многих государствах мира» [Ковалев, Абрамова 2017]. Формы современного развития Китая способствуют дальнейшему распространению идеи «китайской мечты». Эта идея в общем виде содержит в себе общечеловеческие стремления, включая процветание, демократию, гармонию, свободу, равенство, справедливость, верховенство закона, доверие, преданность, патриотизм, братство.

Обозначенная попытка установить новые правила игры для взаимовыгодного сотрудничества Китая и других стран проявляется в выдвинутой Китаем инициативе сотрудничества в рамках концепции «Один пояс - один путь». Реализация проекта откроет перед КНР новые преимущества. Данный проект будет способствовать долгосрочному осуществлению «китайской мечты».

9-10 июня 2018 г. в китайском городе Циндао (провинция Шаньдун) прошел саммит ШОС. По итогам саммита лидеры стран ШОС приняли 17 документов; одним из важнейших можно считать принятие Циндаоской декларации. По итогам заседания Совета глав государств - членов ШОС председатель КНР Си Цзиньпин заявил, что страны организации выступают против торгового протекционизма и за укрепление прозрачной и недискриминационной многосторонней торговой системы. По его словам, на саммите была высказана готовность «углублять взаимодействие в торгово-экономической, инвестиционной, финансовой, сельскохозяйственной сферах, создавать благоприятные условия для торговли и инвестиций с целью открытия новой архитектуры в развитии региональной интеграции на благо народов стран региона, а также для придания нового импульса развитию мировой экономики»1.

Таким образом, китайская мечта является основной идеологией руководства КНР, способной превратить страну в могущественное государство, воплотить в жизнь идею построения «гармоничного общества» и «гармоничного мира». Эффективным методом, приближающим Китай к «китайской мечте», является восприятие западных достижений путем комбинирования форм капитализма и социализма, свободного рынка и государственного регулирования, торгового доминирования и идеологической ориентации, осуществление модернизации с китайской спецификой. Многие авторы говорят о концепции «мягкой силы» Китая.

${ }^{1}$ РИА «Новости». Официальный сайт. Доступ: https://ria.ru/world/ 
В соответствии с концепцией Дж. Ная, американского ученого, автора понятия «мягкая сила», в ее состав входят три базовых компонента: привлекательность системы ценностей государства, привлекательность его культуры, эффективность невоенных механизмов внешней политики [Nye 2012].

«Мягкая сила» Китая проявляется в эффективности реализации внешнеполитической стратегии КНР и способствует решению проблем внутрирегионального развития. «Мягкая сила» Китая содержит в себе государственные интересы и национальные приоритеты, что представляет ценностную основу построения «гармоничного общества» в Китае. Благодаря «мягкой силе» регионы КНР получают максимальный эффект развития, компании выходят на новый международный уровень, совершенствуются технологии, интенсивно развиваются наука и образование. Особое внимание КНР уделяет созданию позитивного образа в мире, чему способствуют брендинговые стратегии, наиболее эффективно осуществляющиеся в процессе трансграничного и приграничного сотрудничества. Внутри государства эффект «мягкой силы» позволяет сохранять устойчивый экономический рост, внутриполитическую стабильность, способствует развитию внутренних регионов, что в совокупности и приближает Китай к осуществлению «китайской мечты».

Согласно заявлениям китайского правительства, концепция «Один пояс один путь» преследует те же цели, что и «Китайская мечта». Это:

1) содействие всеобъемлющей и устойчивой безопасности в Азии на основе взаимовыгодного сотрудничества, мирного разрешения споров, развития партнерских, гармоничных отношений между странами;

2) развитие культурного обмена между странами, что будет способствовать совместному развитию различных цивилизаций. Основными принципами инициативы «Один пояс - один путь» являются взаимная выгода, совместное развитие и соблюдение интересов всех народов, населяющих страны, в пределах реализации проекта.

\section{Список литературы}

Борох Л.Н. 1984. Общественная мысль Китая и социализм (начало ХХ века). М.: Наука. 300 с.

Киссинджер Г. 2014. O Kumaе. М.: АСТ. 635 с.

Ковалев С.М., Абрамова Н.А. 2017. Интерпретация содержания новейшей идеологии КНР «Китайская мечта» в исторической ретроспективе. - Россия и Китай: Проблемы стратегического взаимодействия: сборник Восточного центра. 2017. С. 56-60.

Ознос Э. 2016. Век амбиций: богатство, истина и вера в новом Китае. М.: АСТ. $528 \mathrm{c}$.

Политология (под ред. М.А. Василика, И.Е. Тимерманиса). 2013. М.: Проспект. 624 c.

Скрипкарь М.В., Шамшурин Д.А. 2016. Инициатива «Один пояс и один путь» и концепция «Китайская мечта»: точки соприкосновения. - Актуальные проблемы гуманитарных и естественных наук. № 9-1. С. 267-269.

Чжао Чуньфу. 1999. Конфуцианская этика и модернизация: конфликт и интеграция. - Китай, китайская цивилизация и мир. История, современность, перспективы: материалы X Международной научной конференции. Москва, 2224 сентября. 1999 г. Ч. ІІ: Китай на пути модернизации и реформ. М.: ИДВ РАН.

Needham J. 1956. Science and Civilization in China: History of Scientific Thought. Vol. 2. History of Scientific Thought. Cambridge, UK: University Press.

Nye J.S. 2012. Why China Is Weak on Soft Power. - The New York Times. 18 January. 
URL: www.nytimes.com/2012/01/18/opinion/why-china-is-weak-on-soft-power. html?_r=0 (accessed 07.06.2018).

Wang Wei, postgraduate student at the Faculty of Sociology, Lomonosov Moscow State University (bld. 33, 1 Leninskie Gory St, Moscow, Russia, 119234; wang.wei@bk.ru)

\title{
SOME QUESTIONS OF THE SOCIO-POLITICAL COURSE «THE CHINESE DREAM OF THE GREAT RENAISSANCE OF THE CHINESE NATION»
}

\begin{abstract}
The article considers two concepts: the "Chinese dream» and "One belt - one way", and historical transformation of these concepts. Many political scientists perceived the concept of the Chinese dream as a possible rejection of national traditions. Westernization of China allowed it to borrow all the best from western experience in order to narrow its disparity with the leading powers. The chosen strategy can be projected to the other states, and that will neutralize China's exclusivity. However, in the race and rivalry between the great powers: the US, Russia and China, and the use of nuclear weapons and constant rivalry pose a threat to the preservation of the civilization and peace in the whole world. That is why it is necessary to move from realization of the "national dream» to building a system of stable coexistence and peace. The author notes that the concept "One belt - one way» can act as a mechanism for realizing the Chinese dream, or as its alternative. The further implementation of the project will show it.
\end{abstract}

Keywords: Chinese dream, socio-political course, Chinese nation, national revival, People's Republic of China, China, project "One belt - one way», westernization

ДЕВЯТОВ Руслан Сергеевич - эксперт Фонда поддержки межнациональной культуры и общественных международных отношений (109064, Россия, г. Москва, ул. Спартаковская, 19, стр. 3; devjatov_ruslan@bk.ru)

\section{АКТУАЛЬНЫЕ ПРОБЛЕМЫ СОВРЕМЕННОЙ КУЛЬТУРНОЙ ПОЛИТИКИ (НА ПРИМЕРЕ ФРГ)}

\begin{abstract}
Аннотация. Современное общество переживает не просто трансформацию, а проходит через метаморфозу, формирующую новое, не известное ранее общество и порождающую процессы, которыми человечество пока не научилось управлять. Это требует поиска инновационных решений, многие из которых лежат в сфере культуры, понимаемой широко - как многофункциональная и мультимодальная сфера деятельности. Культура перестает быть только художественным отражением реальности, она становится двигателем современной креативной экономики. В современной Германии самые разные политические силы участвуют в определении и реализации культурной политики, причем крайне правые политики «Альтернативы для Германии» закладывают в контент культурного дискурса и такие понятия, как «народ", «нация», «ведущая германская культура», противопоставляя их другому понятийному ряду: «мультикультурализм», «глобализация», «интернационализация». Концентрированным отражением политики нового правительства ФРГ в сфере культуры является коалиционное соглашение между ХДС/ ХСС, СДПГ и СвДПГ.
\end{abstract}

Ключевые слова: трансформация, метаморфоза, инновации, креативная экономика, культурная политика, понятийный ряд, коалиционное соглашение

$\mathrm{B}$ сложной и конфликтной политической атмосфере Германии во втором десятилетии XXI в. одним из ведущих направлений публичной политики во все большей степени становится политика в сфере культуры. Она отражает не 